Author affiliations and support information (if applicable) appear at the end of this article.

Published at jco.org on September 11, 2017

Clinical trial information: NCT01907100.

Corresponding author: Giorgio Scagliotti, MD, PhD, University of Turin, Department of Oncology, San Luigi Hospital, Regione Gonzole 10, 10043 Orbassano, Torino, Italy; e-mail: giorgio.scagliotti@unito.it.

C 2017 by American Society of Clinical Oncology

0732-183X/17/3531w-3591w/\$20.00

\title{
Nintedanib Plus Pemetrexed/Cisplatin in Patients With Malignant Pleural Mesothelioma: Phase II Results From the Randomized, Placebo-Controlled LUME-Meso Trial
}

Federica Grosso, Nicola Steele, Silvia Novello, Anna K. Nowak, Sanjay Popat, Laurent Greillier, Thomas John, Natasha B. Leighl, Martin Reck, Paul Taylor, David Planchard, Jens Benn Sørensen, Mark A. Socinski, Ute von Wangenheim, Arsène Bienvenu Loembé, José Barrueco, Nassim Morsli, and Giorgio Scagliotti

\section{$\begin{array}{llllllll}\text { A } & \text { B } & \text { S } & \text { T } & \text { R } & \text { A } & \text { C } & \text { T }\end{array}$}

\section{Purpose}

LUME-Meso is a phase II/III randomized, double-blind trial designed to assess efficacy and safety of nintedanib plus chemotherapy as first-line treatment of malignant pleural mesothelioma (MPM). Phase II results are reported here.

\section{Patients and Methods}

Chemotherapy-naïve patients with unresectable, nonsarcomatoid MPM (Eastern Cooperative Oncology Group performance status 0 to 1 ), stratified by histology (epithelioid or biphasic), were randomly assigned in a 1:1 ratio to up to six cycles of pemetrexed and cisplatin plus nintedanib (200 mg twice daily) or placebo followed by nintedanib plus placebo monotherapy until progression. The primary end point was progression-free survival (PFS).

\section{Results}

Eighty-seven patients were randomly assigned. The median number of pemetrexed and cisplatin cycles was six; the median treatment duration for nintedanib was 7.8 months and 5.3 months for placebo. Primary PFS favored nintedanib (hazard ratio $[\mathrm{HR}], 0.56 ; 95 \% \mathrm{Cl}, 0.34$ to $0.91 ; P=.017$ ), which was confirmed in updated PFS analyses (HR, 0.54;95\% $\mathrm{Cl}, 0.33$ to $0.87 ; P=.010)$. A trend toward improved overall survival also favored nintedanib ( $\mathrm{HR}, 0.77 ; 95 \% \mathrm{Cl}, 0.46$ to $1.29 ; P=.319)$. Benefit was evident in epithelioid histology, with a median overall survival gain of 5.4 months $(H R$, $0.70 ; 95 \% \mathrm{Cl}, 0.40$ to $1.21 ; P=.197 ;$ median [nintedanib $v$ placebo], 20.6 months $v 15.2$ months) and median PFS gain of 4.0 months (HR, $0.49 ; 95 \% \mathrm{Cl}, 0.30$ to $0.82 ; P=.006$; median [nintedanib $v$ placebo], $9.7 \vee 5.7$ months). Neutropenia was the most frequent grade $\geq 3$ adverse event (AE; nintedanib $43.2 \% v$ placebo $12.2 \%)$; rates of febrile neutropenia were low $(4.5 \%$ in nintedanib group $v 0 \%$ in placebo group). AEs leading to discontinuation were reported in $6.8 \%$ of those receiving nintedanib versus $17.1 \%$ of those in the placebo group.

\section{Conclusion}

Addition of nintedanib to pemetrexed plus cisplatin resulted in PFS improvement. AEs were manageable. The clinical benefit was evident in patients with epithelioid histology. The confirmatory phase III part of the study is ongoing.

\section{J Clin Oncol 35:3591-3600. (C) 2017 by American Society of Clinical Oncology}

\section{INTRODUCTION}

Malignant pleural mesothelioma (MPM) is a rare but aggressive cancer usually caused by asbestos exposure. ${ }^{1}$ The incidence of MPM is expected to have peaked, or to peak in the coming years in countries that have carefully regulated the commercial use of asbestos. ${ }^{2}$ However, asbestos remains in use in many regions, which are likely to see a corresponding increase in cases of MPM. ${ }^{3,4}$
MPM is typically diagnosed at an advanced stage and overall prognosis is poor, with median overall survival (OS) reported to be as short as 7 months. ${ }^{1}$ For patients with unresectable disease, systemic first-line treatment with pemetrexed and cisplatin is the standard of care, ${ }^{5,6}$ on the basis of a phase III study that reported an increase of 2.8 months in OS compared with cisplatin alone (12.1 $v 9.3$ months). ${ }^{7}$ There are currently no approved agents for second-line treatment, although pemetrexed-based regimens (if not used 
as first-line therapy), vinorelbine, gemcitabine, or enrollment in a clinical trial are recommended by some guidelines. ${ }^{5,6}$ Studies with the multitargeted small-molecule tyrosine kinase inhibitors cediranib, dasatinib, sorafenib, and sunitinib have failed to show adequate clinical activity as second-line treatments when used as monotherapy. ${ }^{8-11}$ There is a clear need for more effective treatments. Although several clinical trials have evaluated novel compounds in combination with pemetrexed and cisplatin as first-line treatment, so far there have been few advances. In an open-label, phase III study (Mesothelioma Avastin Cisplatin Pemetrexed Study [MAPS]), the addition of bevacizumab to pemetrexed and cisplatin (with maintenance bevacizumab) significantly increased OS (median OS, $18.8 v 16.1$ months; hazard ratio [HR], 0.77; $P=.017) .^{5}$ Data from the MAPS study ${ }^{5}$ support the concept that inhibition of signaling by the vascular endothelial growth factor (VEGF) pathway may be a potential treatment option for MPM. ${ }^{12}$

Nintedanib is an oral, twice-daily, angiokinase inhibitor targeting VEGF receptors 1,2 , and3, platelet-derived growth factor receptors $\alpha / \beta$, fibroblast growth factor (FGF) receptors 1,2 , and 3, as well as Src and Abl kinase signaling. ${ }^{13,14}$ At the time this study was designed, VEGF signaling was known to play an important role in mesothelioma pathophysiology. ${ }^{15-18}$ Other signaling pathways inhibited by nintedanib had also been proposed as valid therapeutic targets, including the Src and Abl kinases, which are involved in MPM cell migration, ${ }^{19,20}$ and FGF, which is overexpressed in MPM tumor samples. $^{21}$ Targeting more than one pathway may have the potential for increased efficacy, and this provided the rationale for investigating nintedanib in MPM. Unlike previously investigated small-molecule tyrosine kinase inhibitors, nintedanib has a manageable safety profile in combination with commonly used chemotherapy agents, making it suitable to be investigated in combination with standard-of-care firstline cisplatin plus pemetrexed. ${ }^{22-26}$

Here we report the results of the phase II part of LUME-Meso (ClinicalTrials.gov identifier: NCT01907100), an ongoing phase II/ III study designed to evaluate the safety and efficacy of standard chemotherapy combined with nintedanib or placebo in the firstline treatment of patients with unresectable MPM (clinical trial identifier: NCT01907100).

\section{PATIENTS AND METHODS}

\section{Study Design and Patients}

The LUME-Meso study was initially designed as a phase II, doubleblind, randomized trial of nintedanib or placebo in combination with

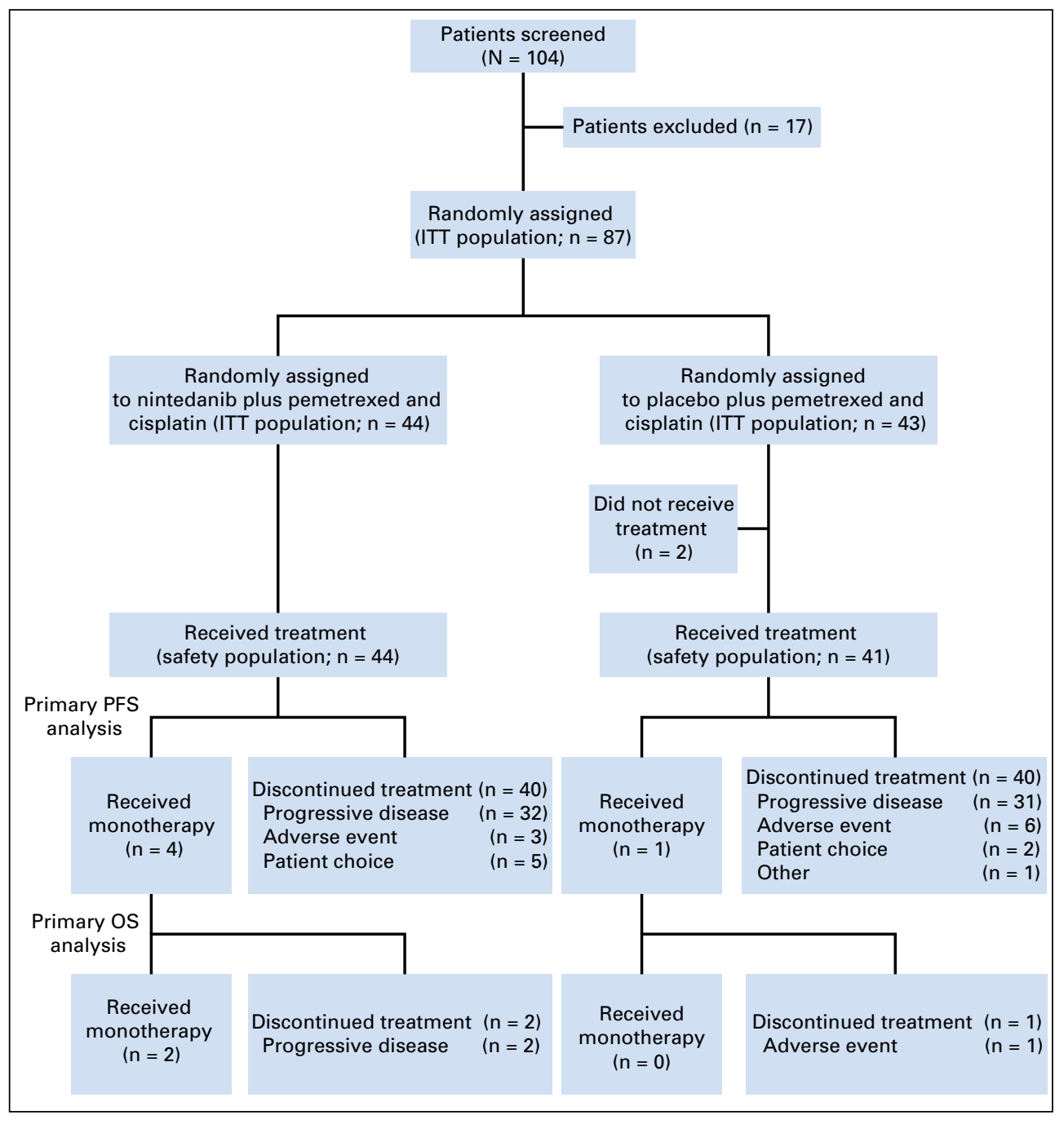

Fig 1. Patient disposition. ITT, intention to treat; OS, overall survival; PFS, progressionfree survival. 
standard treatment of pemetrexed and cisplatin, followed by continuing nintedanib or placebo monotherapy as first-line treatment of patients with unresectable nonsarcomatoid MPM. The phase II part of the study was conducted at 18 sites in eight countries (Appendix Table A1, online only).

Eligible patients were $\geq 18$ years of age, with histologically confirmed, unresectable epithelioid or biphasic MPM (Eastern Cooperative Oncology Group performance status 0 or 1) and measurable disease according to Response Evaluation Criteria In Solid Tumors modified for mesothelioma (mRECIST). ${ }^{27}$ Key exclusion criteria were previous systemic chemotherapy for MPM and sarcomatoid MPM (Appendix, online only).

Health authorities and independent ethics committees or institutional review boards at each country/center approved the protocol on the basis of local regulations. The study was conducted in accordance with good clinical practice and followed the guiding principles of the Declaration of Helsinki, as well as local laws and regulations. All patients provided written informed consent.

\section{Randomization, Patient Allocation, and Procedures}

Patients were randomly assigned in a 1:1 ratio to receive nintedanib or placebo. Randomization was stratified by histology (epithelioid or biphasic).

Treatment with pemetrexed and cisplatin and either nintedanib or matching placebo was given in 21-day courses. Pemetrexed and cisplatin were administered for a maximum of six cycles at the following standard dosages: $500 \mathrm{mg} / \mathrm{m}^{2}$ intravenous (IV) over 10 minutes on day 1 of each 21 day cycle for pemetrexed, and $75 \mathrm{mg} / \mathrm{m}^{2}$ IV over 2 hours on day 1 of each 21-day cycle for cisplatin. Nintedanib was given orally at $200 \mathrm{mg}$ twice daily on days 2 through 21 of each 21-day cycle. Patients who did not experience progression during the combination therapy phase continued to receive nintedanib or placebo monotherapy until disease progression, undue toxicity, and withdrawal of consent or death. Predefined dose reduction was allowed to manage adverse events (AEs).

Tumor-response assessment by computed tomography was performed at baseline (within 4 weeks before first treatment) and then every 6 weeks ( \pm 1 week) and continued until progression or discontinuation from study. Tumor response was evaluated using mRECIST $^{27}$ according to investigator assessment.

Safety was assessed regularly according to the protocol using US National Cancer Institute Common Terminology Criteria for Adverse Events, version 3.0. AEs of interest were categorized using standardized Medical Dictionary for Regulatory Activities-queries tailored to special search categories.

\section{End Points}

The primary end point was progression-free survival (PFS) by investigator assessment, defined as the time from random assignment to the date of disease progression according to mRECIST, ${ }^{27}$ or death from any cause. OS and objective response were secondary end points.

\section{Statistical Analysis}

For the phase II portion of the study, the sample size was calculated to provide an initial assessment of the safety and efficacy of adding nintedanib to pemetrexed and cisplatin, and was based on an assumed HR for PFS of 0.75 (median PFS, 8 months for the nintedanib plus pemetrexed and cisplatin combination $v 6$ months for the placebo-pemetrexed-cisplatin regimen). Originally, the primary analysis of PFS was planned after 65 PFS events (approximately 75\% of all randomly assigned patients). The target sample size was, therefore, 86 patients. This was considered sufficient to have a high probability of detecting a true signal of treatment benefit.

Following the data monitoring committee recommendation to modify the trial into a confirmatory phase III study, and after consultation with regulatory authorities, the phase II part of the trial was unblinded for the primary PFS analysis to refine assumptions for sample size calculation in phase III (data cutoff, March 4, 2016). The number of phase II PFS events (ie, progression and deaths) reached at that time was 69. The primary OS analysis and corresponding updated PFS analysis was to be performed after approximately 61 deaths.

Efficacy analyses included all randomly assigned patients, using the intention-to-treat principle. PFS and OS were analyzed using KaplanMeier methods. $P$ values were calculated from the two-sided stratified logrank test. The objective response rate was compared between treatment groups using a logistic regression model. All statistical analyses were performed using SAS version 9.4 (SAS Institute, Cary, NC) and are intended to be descriptive.

The phase III part started recruitment in May 2016, remains blinded, and will be used for the confirmatory analysis of this trial. The patients included in phase II will not be counted toward phase III recruitment.

\section{RESULTS}

\section{Patients}

Between September 2013 and December 2014, 104 patients were screened and 87 patients were randomly assigned to treatment with pemetrexed and cisplatin and either nintedanib $(\mathrm{n}=44)$ or matching placebo $(n=43)$. Two patients in the placebo arm

\begin{tabular}{|c|c|c|}
\hline Characteristic & $\begin{array}{l}\text { Nintedanib Plus } \\
\text { Pemetrexed and } \\
\text { Cisplatin } \\
(n=44)\end{array}$ & $\begin{array}{l}\text { Placebo Plus } \\
\text { Pemetrexed and } \\
\text { Cisplatin } \\
(n=43)\end{array}$ \\
\hline Median age, years (range) & 68 (39-79) & $66(44-80)$ \\
\hline \multicolumn{3}{|l|}{ Sex, No. (\%) } \\
\hline Male & $34(77)$ & $35(81)$ \\
\hline Female & $10(23)$ & 8 (19) \\
\hline \multicolumn{3}{|l|}{ Race, No. (\%) } \\
\hline White & $38(86)$ & $38(88)$ \\
\hline Missing data* & $6(14)$ & $5(12)$ \\
\hline \multicolumn{3}{|l|}{ ECOG performance status, No. (\%) } \\
\hline 0 & $25(57)$ & $21(49)$ \\
\hline 1 & 19 (43) & $22(51)$ \\
\hline \multicolumn{3}{|l|}{ Smoking history, No. (\%) } \\
\hline Never smoker & $22(50)$ & $23(54)$ \\
\hline Ex-smoker & $21(48)$ & $20(47)$ \\
\hline Current smoker & $1(2)$ & 0 \\
\hline $\begin{array}{l}\text { Previous exposure to asbestos, } \\
\text { No. (\%) }\end{array}$ & $28(64)$ & $33(77)$ \\
\hline $\begin{array}{l}\text { Median time since first } \\
\text { histologic diagnosis, } \\
\text { months (range) }\end{array}$ & $1.5(0.5-24.3)$ & $1.7(0.2-13.0)$ \\
\hline \multicolumn{3}{|l|}{ Histology, No. (\%) } \\
\hline Epithelioid & $39(89)$ & $38(88)$ \\
\hline Biphasic & $5(11)$ & $5(12)$ \\
\hline \multicolumn{3}{|l|}{$\begin{array}{l}\text { Tumor stage at screening } \\
\text { (UICC/AJCC), No. (\%) }\end{array}$} \\
\hline 1 & $3(7)$ & 0 \\
\hline II & $2(5)$ & $10(23)$ \\
\hline III & $26(59)$ & $17(40)$ \\
\hline IV & $13(30)$ & $15(35)$ \\
\hline Missing data & 0 & $1(2)$ \\
\hline Previous radiotherapy, + No. (\%) & $9(21)$ & $4(9)$ \\
\hline $\begin{array}{l}\text { Previous surgery (pleurectomy/ } \\
\text { debulking/extrapleural } \\
\text { pneumonectomy), No. (\%) }\end{array}$ & $5(11)$ & $2(5)$ \\
\hline \multicolumn{3}{|c|}{$\begin{array}{l}\text { Abbreviations: ECOG, Eastern Cooperative Oncology Group; UICC/AJCC } \\
\text { Union Internationale Contre le Cancer/American Joint Committee on Cancers. } \\
{ }^{*} \text { Race was not recorded in France according to local regulations. } \\
\text { †The majority of radiotherapy was prophylactic and low dose }(<30 \mathrm{~Gy} \text {. }\end{array}$} \\
\hline
\end{tabular}




\begin{tabular}{|lcc|}
\hline \multicolumn{3}{|c|}{ Table 2. Dose Intensity } \\
\hline $\begin{array}{c}\text { Mean Dose } \\
\text { Intensity }\end{array}$ & $\begin{array}{c}\text { Nintedanib Plus Pemetrexed and } \\
\text { Cisplatin, \% (SD) } \\
(\mathrm{n}=44)\end{array}$ & $\begin{array}{c}\text { Placebo Plus Pemetrexed } \\
\text { and Cisplatin, \% (SD) } \\
(\mathrm{n}=41)\end{array}$ \\
\hline $\begin{array}{l}\text { Nintedanib/ } \\
\text { placebo }\end{array}$ & $92.2(12.0)$ & $98.0(5.1)$ \\
$\begin{array}{l}\text { Pemetrexed } \\
\text { Cisplatin }\end{array}$ & $95.8(7.9)$ & $98.8(6.6)$ \\
\hline Abbreviation: SD, standard deviation. & $98.1(6.1)$ \\
\hline
\end{tabular}

never received any study treatment because of contraindications. Details of patient disposition are shown in Figure 1.

Clinical characteristics and demographics in each arm showed similar baseline parameters (Table 1). Overall, the median age of patients was 67 years, $79 \%$ of patients were male, $89 \%$ had epithelioid histology, and $70 \%$ had known previous exposure to asbestos. Five (11.4\%) patients in the nintedanib group and two $(4.7 \%)$ patients in the placebo group had previous surgery.

Median duration of nintedanib/placebo treatment was 7.8 months (range, 0.1 to 33.2 months) in the nintedanib group and 5.3 months (range, 0.4 to 28.9 months) in the placebo group at the time of the primary OS analysis. Median follow-up was 29.0 months (95\% CI, 26.9 to 33.1 months).

The median number of pemetrexed and cisplatin courses was six in both treatment groups. In the nintedanib arm, 26 patients (59.1\%) received six cycles of pemetrexed and 23 patients $(52.3 \%)$ received six cycles of cisplatin. In the placebo arm, 22 patients (53.7\%) received six cycles of pemetrexed and 21 patients $(51.2 \%)$ received six cycles of cisplatin. Pemetrexed dose reductions were observed in 11 patients $(25.0 \%)$ treated with nintedanib and two $(4.9 \%)$ in the placebo arm, whereas cisplatin dose reductions were observed in nine patients $(20.5 \%)$ treated with nintedanib and five $(12.2 \%)$ in the placebo arm.
Nintedanib dose reductions were required in 17 patients (38.6\%), of whom five patients $(11.4 \%)$ required a second dose reduction. Placebo dose reduction was required in seven patients (17.1\%). Mean dose intensities for chemotherapy and for nintedanib and placebo are listed in Table 2.

\section{Efficacy}

The main efficacy results for the overall population as well as the population analyzed by histology are listed in Table 3. Nintedanib treatment improved PFS compared with placebo. This finding was observed at the primary PFS analysis with 69 PFS events (HR, $0.56 ; 95 \% \mathrm{CI}, 0.34$ to $0.91 ; P=.017$ ) and confirmed at the updated analysis (HR, $0.54 ; 95 \% \mathrm{CI}, 0.33$ to $0.87 ; P=.010)$ with 72 PFS events.

When analyzed by histology, improvement in PFS was evident in patients with epithelioid histology (HR, 0.49; 95\% CI, 0.30 to $0.82 ; P=.006)$. The number of patients with biphasic histology MPM $(n=10)$ was too low to provide a reliable estimate of the treatment effect. Kaplan-Meier curves of PFS for the overall patient population and the epithelioid population at the time of the primary OS analysis are shown in Figures $2 \mathrm{~A}$ and $2 \mathrm{~B}$; treatment with nintedanib improved median PFS by 3.7 months for the overall population and by 4.0 months for the epithelioid population.

At the time of the primary OS analysis, 62 OS events (71\%) had occurred. Analysis of OS showed an improvement favoring nintedanib treatment in all patients (median OS, 18.3 months in nintedanib group $v 14.2$ months in placebo group; HR, 0.77; 95\% CI, 0.46 to $1.29 ; P=.319$; Table 3 and Fig 2C). For patients with epithelioid histology the median OS was 20.6 months with nintedanib $v 15.2$ months with placebo (HR, 0.70; 95\% CI, 0.40 to 1.21; $P=.197$; Table 3 and Fig 2D).

The effect of nintedanib on PFS and OS was consistent across the subgroups, with the exception of patients with biphasic histology (Fig 3).More than half of patients in each treatment group

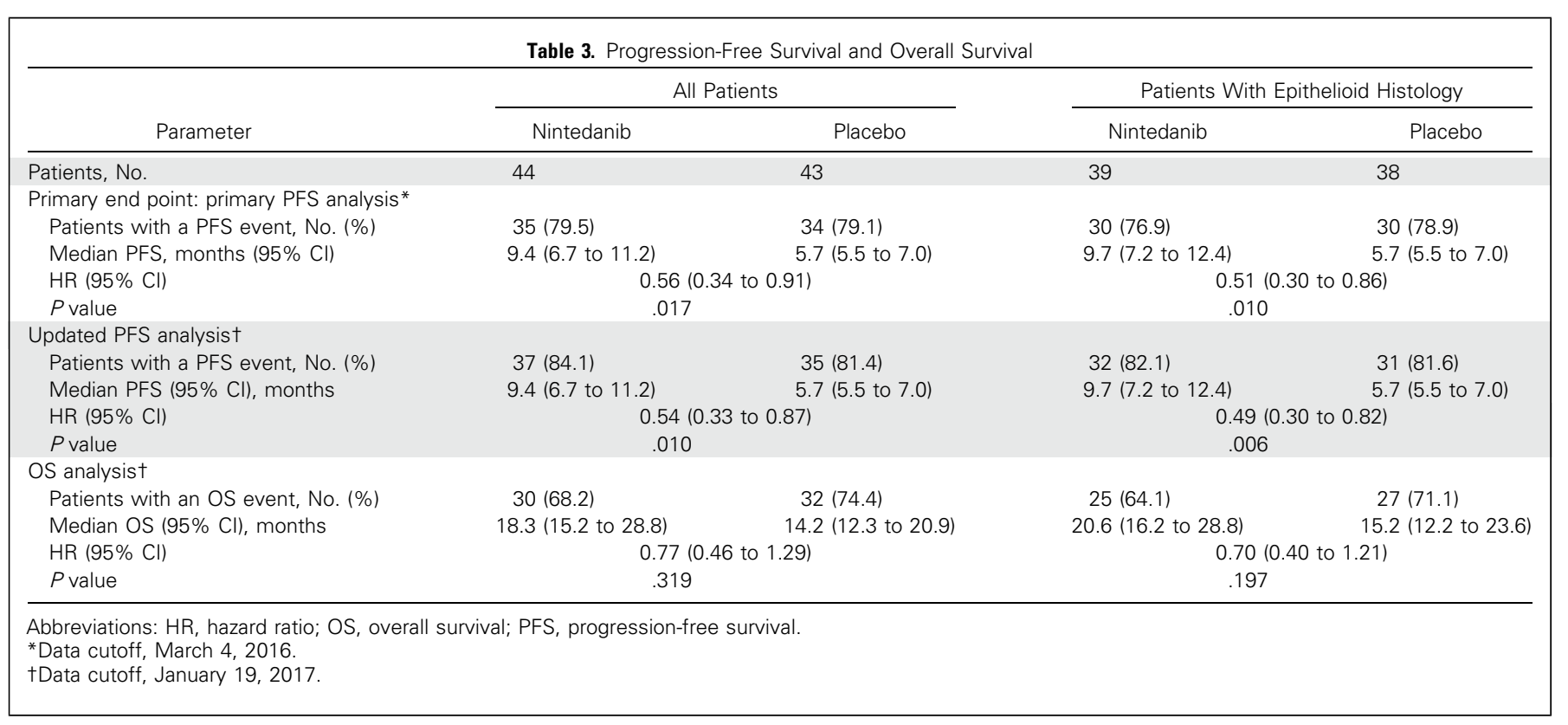




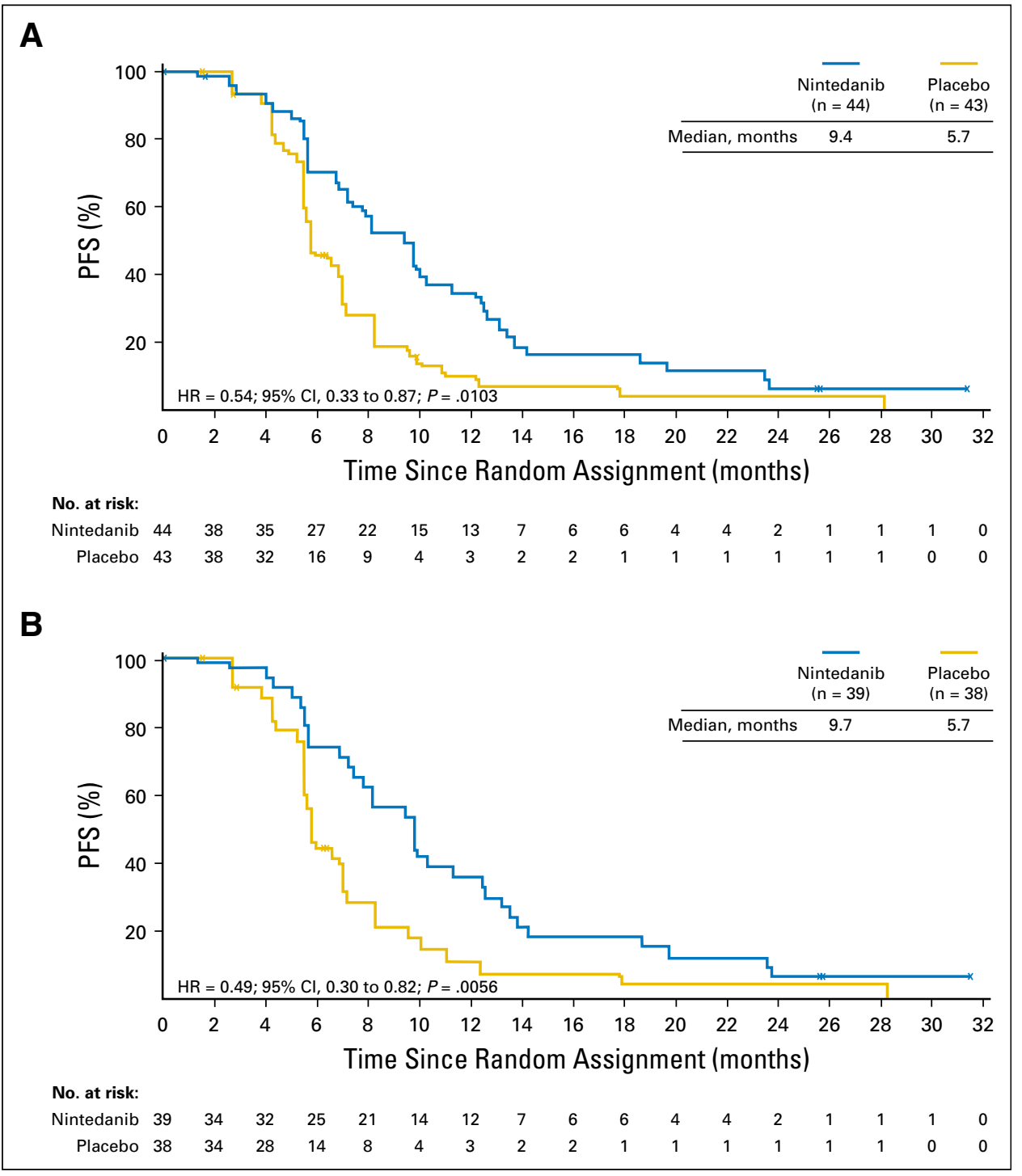

Fig 2. Updated progression-free survival (PFS) and primary overall survival (OS). (A) KaplanMeier curves for PFS, and (B) PFS in patients with epithelioid histology. (C) Kaplan-Meier curves for OS, and (D) OS in patients with epithelioid histology. HR, hazard ratio.

(nintedanib 64\% $v$ placebo 70\%) received subsequent therapy (Appendix Table A2, online only).

The best overall tumor response according to mRECIST criteria showed more objective responses (all partial responses) in the nintedanib arm $(\mathrm{n}=25 ; 56.8 \%)$ than in the placebo arm ( $\mathrm{n}=19 ; 44.2 \%$; odds ratio, $1.66 ; 95 \% \mathrm{CI}, 0.72$ to 3.9 ).

\section{Safety and Adverse Events}

All patients experienced at least one $\mathrm{AE}$ of any grade and nearly all patients in the nintedanib (97.7\%) and placebo (97.6\%) groups experienced an investigator-defined drug-related AE. The most frequently reported AEs ( $\geq 60 \%$ of patients, any CTCAE grade) in the nintedanib arm and more frequent with nintedanib than placebo were diarrhea and neutropenia. Table 4 lists the most common AEs by group terms. Grade $\geq 3$ AEs were reported in 35 patients $(79.5 \%)$ in the nintedanib arm and 22 patients $(53.7 \%)$ in the placebo arm. There was an increased frequency of grade $\geq 3$ group-term AEs of neutropenia in the nintedanib arm (43.2\% $v$ $12.2 \%$ ), although the rate of febrile neutropenia (group term) was low $(4.5 \% ; n=2)$ in the nintedanib arm and not reported with placebo. There were no reports of sepsis with nintedanib.

Incidence of AEs (group terms) commonly associated with anti-angiogenic agents were either balanced between treatment arms or reported in lower numbers of patients in the nintedanib arm. The events of interest (nintedanib $v$ placebo) included bleeding $(11.4 \% v 12.2 \%)$, GI perforation ( $0 \% v 2.4 \%)$, thromboembolism $(9.1 \% \vee 17.1 \%)$, and venous thromboembolism $(6.8 \% v 14.6 \%)$. There were no reports of arterial thromboembolism.

Serious AEs (SAEs) occurred in 18 patients (40.9\%) in the nintedanib arm and in 17 patients $(41.5 \%)$ in the placebo arm. The most frequent SAEs (all grades; nintedanib $v$ placebo) were neutropenia $(9.1 \%[\mathrm{n}=4] v 2.4 \%[\mathrm{n}=1])$, diarrhea $(6.8 \%[\mathrm{n}=3] \vee 0)$, pyrexia $(6.8 \%[\mathrm{n}=3] \vee 4.9 \%[\mathrm{n}=2])$, and pulmonary embolism $(2.3 \%[\mathrm{n}=1] v 9.8 \%[\mathrm{n}=4]$, respectively). Three patients in the placebo arm died as a result of SAEs: one patient from disease progression, one patient from general physical health deterioration, and one patient from both disease progression and treatment-related nephrotic syndrome. One fatal SAE was reported in the nintedanib group (disease progression unrelated to treatment). 


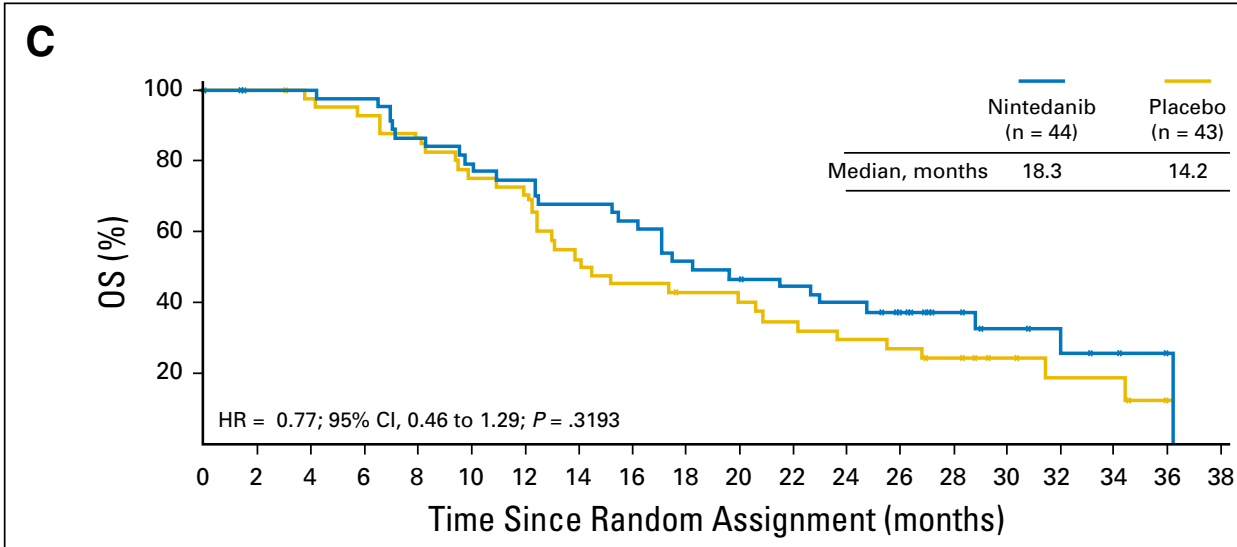

No. at risk:

$\begin{array}{lllllllllllllllllllllll}\text { Nintedanib } & 44 & 43 & 43 & 42 & 37 & 34 & 32 & 29 & 27 & 22 & 20 & 18 & 16 & 13 & 9 & 6 & 4 & 3 & 1 & 0\end{array}$

$\begin{array}{lllllllllllllllllllll}\text { Placebo } & 43 & 41 & 39 & 37 & 34 & 30 & 28 & 21 & 18 & 16 & 15 & 13 & 11 & 10 & 8 & 5 & 3 & 3 & 0 & 0\end{array}$

D

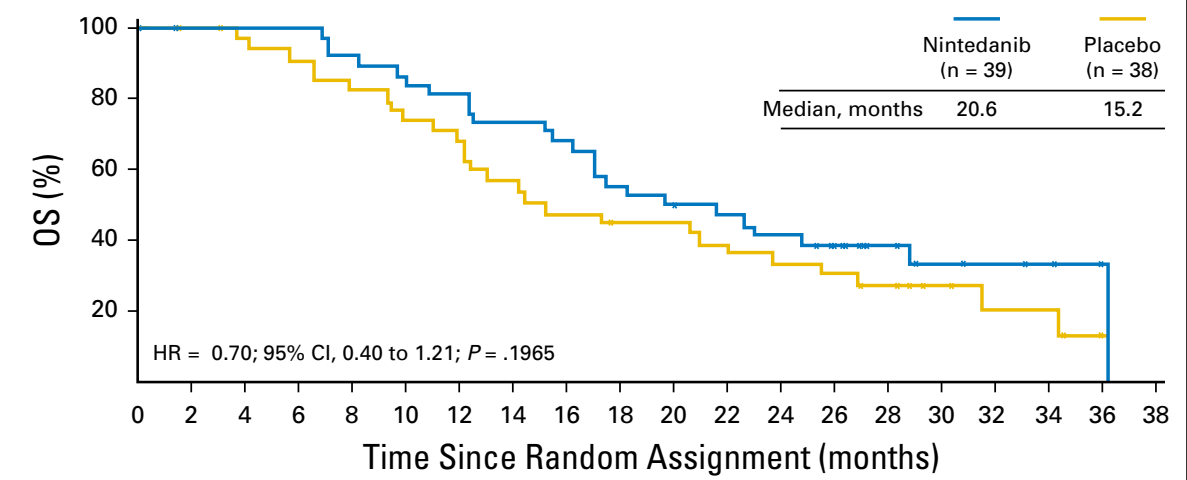

No. at risk:

$\begin{array}{llllllllllllllllllllll}\text { Nintedanib } & 39 & 38 & 38 & 38 & 35 & 33 & 31 & 28 & 26 & 21 & 19 & 17 & 15 & 12 & 8 & 5 & 4 & 3 & 1 & 0\end{array}$ $\begin{array}{llllllllllllllllllllll}\text { Placebo } & 38 & 36 & 34 & 32 & 29 & 26 & 24 & 20 & 17 & 15 & 15 & 13 & 11 & 10 & 8 & 5 & 3 & 3 & 0 & 0\end{array}$
Fig 2. (Continued).
Three patients $(6.8 \%)$ in the nintedanib arm and seven patients $(17.1 \%)$ in the placebo arm experienced AEs leading to permanent discontinuation of last study medication. AEs leading to discontinuation in the nintedanib arm included upper abdominal pain and vomiting in one patient; increased aspartate aminotransferase/blood alkaline phosphatase levels in one patient; and neutropenia, aplasia, and Klebsiella pneumonia in one patient; no patients discontinued treatment because of diarrhea. Fourteen patients $(31.8 \%)$ in the nintedanib arm and six $(14.6 \%)$ in the placebo arm experienced AEs leading to dose reduction of nintedanib or placebo. AEs leading to dose reduction of nintedanib occurring in more than one patient included diarrhea $(9.1 \%)$, increased alanine aminotransferase levels (9.1\%), nausea $(4.5 \%)$, and neutropenia $(4.5 \%)$.

\section{DISCUSSION}

The addition of nintedanib to standard pemetrexed and cisplatin therapy demonstrated improved clinical efficacy in the first-line treatment of patients with MPM, as evidenced by improved PFS with a corresponding improvement in OS and a manageable safety profile. A benefit was observed in patients with epithelioid histology; the median PFS prolongation of 4 months in these patients (with minimal additional toxicity) provided the rationale to proceed to the phase III component of the study. The median OS time of 20.6 months achieved in the epithelioid histology subtype is, to our knowledge, the longest reported in a randomized, doubleblind phase II study.

The positive findings of the MAPS study with the addition of bevacizumab to standard pemetrexed plus cisplatin provide context to our data. The HR for PFS was 0.61 (95\% CI, 0.50 to 0.75 ; median 9.2 months with bevacizumab $v 7.3$ months with placebo) in the MAPS study, whereas the HR for OS was 0.77 (95\% CI, 0.62 to 0.95 ; median 18.2 months with bevacizumab $v 16.1$ months with placebo). In our trial, with all the limitations related to differences between the studies, the HRs for PFS and OS confirm the value of targeting angiogenesis as a treatment approach in MPM. Interestingly, in the MAPS trial, the effect of bevacizumab on survival was more pronounced in patients with sarcomatoid or mixed histology (HR, $0.64 ; 95 \% \mathrm{CI}, 0.40$ to 1.02 ) than in patients with epithelioid histology (OS HR, 0.82; 95\% CI, 0.64 to 1.06). However, between-trial comparisons should be done with caution because of the differences in size (phase II for LUME-Meso $v$ phase 


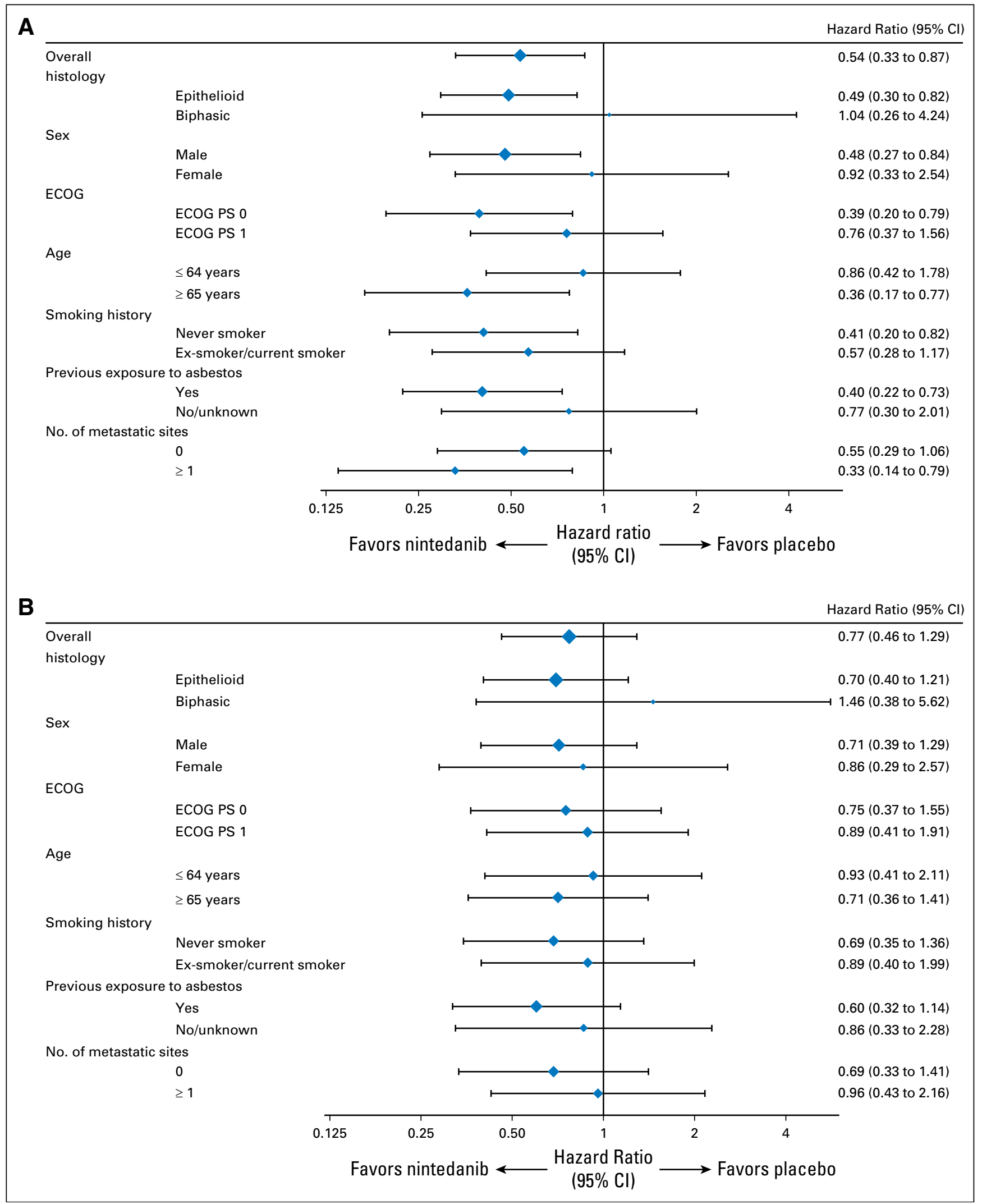

Fig 3. Forest plot of (A) progression-free survival and (B) overall survival by subgroups in all patients. ECOG PS, Eastern Cooperative Oncology Group performance status. 


\begin{tabular}{|c|c|c|c|c|}
\hline \multirow[b]{2}{*}{ Adverse Events } & \multicolumn{2}{|c|}{$\begin{array}{l}\text { Nintedanib Plus Pemetrexed and } \\
\text { Cisplatin, No. }(\% ; n=44)\end{array}$} & \multicolumn{2}{|c|}{$\begin{array}{l}\text { Placebo Plus Pemetrexed and Cisplatin, } \\
\text { No. }(\% ; n=41)\end{array}$} \\
\hline & Any Grade & Grade $\geq 3$ & Any Grade & Grade $\geq 3$ \\
\hline Nausea & $37(84.1)$ & $3(6.8)$ & 36 (87.8) & $3(7.3)$ \\
\hline Fatigue & $33(75.0)$ & $5(11.4)$ & $37(90.2)$ & $4(9.8)$ \\
\hline Diarrhea & 31 (70.5) & $3(6.8)$ & 15 (36.6) & 0 \\
\hline Neutropenia & 29 (65.9) & $19(43.2)$ & $12(29.3)$ & $5(12.2)$ \\
\hline Electrolyte imbalance & $25(56.8)$ & 7 (15.9) & $16(39.0)$ & $4(9.8)$ \\
\hline Infection & $24(54.5)$ & $1(2.3)$ & $21(51.2)$ & $3(7.3)$ \\
\hline Vomiting & $24(54.5)$ & $2(4.5)$ & $21(51.2)$ & $1(2.4)$ \\
\hline Anemia & $20(45.5)$ & $4(9.1)$ & $13(31.7)$ & $2(4.9)$ \\
\hline Liver-related investigation & $20(45.5)$ & $10(22.7)$ & $3(7.3)$ & $1(2.4)$ \\
\hline Abdominal pain & $18(40.9)$ & 0 & $6(14.6)$ & 0 \\
\hline Increased ALT level & $17(38.6)$ & $6(13.6)$ & $1(2.4)$ & $1(2.4)$ \\
\hline Specific liver-related investigation (tailored) & $17(38.6)$ & $6(13.6)$ & $1(2.4)$ & $1(2.4)$ \\
\hline Peripheral neuropathies & $15(34.1)$ & $1(2.3)$ & $11(26.8)$ & 0 \\
\hline Mucositis & 14 (31.8) & 0 & $12(29.3)$ & $1(2.4)$ \\
\hline Thrombocytopenia & $14(31.8)$ & $5(11.4)$ & $5(12.2)$ & 0 \\
\hline Increased AST level & $13(29.5)$ & 0 & $1(2.4)$ & 0 \\
\hline Rash & $12(27.3)$ & 0 & $11(26.8)$ & 0 \\
\hline Increased GGT level & $11(25.0)$ & $6(13.6)$ & $1(2.4)$ & 0 \\
\hline Increased ALKP level & 9 (20.5) & 0 & $1(2.4)$ & 0 \\
\hline Hearing impairment, narrow & $7(15.9)$ & 0 & $10(24.4)$ & 0 \\
\hline Hypertension & $7(15.9)$ & $4(9.1)$ & 6 (14.6) & $1(2.4)$ \\
\hline Dehydration & $6(13.6)$ & $3(6.8)$ & $5(12.2)$ & $1(2.4)$ \\
\hline Pneumonia & $5(11.4)$ & $1(2.3)$ & $4(9.8)$ & $3(7.3)$ \\
\hline Thromboembolic events & $4(9.1)$ & $2(4.5)$ & $7(17.1)$ & $4(9.8)$ \\
\hline Venous thromboembolism & $3(6.8)$ & $2(4.5)$ & $6(14.6)$ & $3(7.3)$ \\
\hline
\end{tabular}

III for MAPS), design (double blind $v$ open label), and patient eligibility (nonsarcomatoid MPM $v$ all histologic subtypes; age of patients $\geq 18$ years $v 18$ to 75 years).

Although inhibition of angiogenesis via VEGF by bevacizumab has been demonstrated as a viable approach, nintedanib combines VEGF receptor inhibition with targeting other pathways: namely, the platelet-derived growth factor pathway, associated with poor prognosis in $\mathrm{MPM}^{28}$ and the FGF receptor pathway, implicated in the pathogenesis of MPM in preclinical studies. ${ }^{12}$ In addition to the inhibition of proangiogenic signaling, preclinical data show that nintedanib strongly reduces the colony-forming capacity and migratory activity of MPM cell lines - this appears to be a direct effect on the mesothelioma cells themselves ${ }^{29,30}$ - and inhibits MPM tumor growth in human xenograft models. ${ }^{29}$ It is possible that Src inhibition by nintedanib ${ }^{14}$ may add to the clinical activity in patients with MPM. The broad inhibition profile of nintedanib, coupled with the direct antitumor activity, may account for the promising results observed.

The overall safety profile of nintedanib in combination with chemotherapy was as expected from previous studies. AEs were manageable. Although the incidence of diarrhea reported here was higher than reported with nintedanib when given with docetaxel in a study of lung cancer, ${ }^{24}$ rates are similar to those previously reported when nintedanib was given with a doublet chemotherapy, such as with paclitaxel plus carboplatin or modified infusional fluorouracil, leucovorin, and oxaliplatin (FOLFOX6). ${ }^{23,31}$ Although diarrhea was common, it was mainly of low grade, reversible with dose interruption, and no patients permanently discontinued study medication because of this event. Clinical experience with nintedanib in non-small cell lung cancer indicates that diarrhea can be managed with appropriate medication or existing dose reduction protocols. ${ }^{32}$ Certain grade $\geq 3$ AEs were reported more frequently in the nintedanib arm than in the placebo arm, including increased liver enzyme levels and neutropenia, although complications of the latter, such as febrile neutropenia, were low; sepsis was also not reported. Liver enzyme elevations have been reported previously with nintedanib in combination with docetaxel and are generally reversible and manageable. ${ }^{24}$ Incidences of AEs typically associated with VEGF/VEGF-receptor inhibitors were either balanced between the groups, as in the case of hypertension, or reported in fewer patients in the nintedanib arm.

The dose intensity of the pemetrexed plus cisplatin regimen was maintained in the presence of nintedanib. The median number of pemetrexed plus cisplatin courses was six in both groups. Approximately twice as many patients in the nintedanib group, compared with the placebo group, experienced an AE leading to dose reduction of nintedanib or placebo; however, the rate of AEs leading to discontinuation was higher in the placebo group. The proportion of patients who received poststudy treatment was also similar between groups (nintedanib, 64\% $v$ placebo, 70\%), indicating that addition of nintedanib to standard doublet chemotherapy did not adversely influence patients' ability to receive subsequent treatments.

The strengths of this phase II study include a randomized double-blind design, removing potential sources of bias. Although 
recent research has suggested that PFS may not be a valid surrogate end point for OS in MPM, ${ }^{33}$ analyses were conducted on small, phase II studies, most of which included only one treatment arm and did not include pemetrexed. These factors may have had an effect on the lack of observed correlation between PFS and OS. The trend toward improved OS in our study is reassuring and adds to the evidence from other larger trials that have shown an association. ${ }^{5,7}$ Several limitations should be considered. These include the relatively small sample size requiring confirmation of results, and the small number of patients with biphasic histology, which limited the interpretation of results in this subgroup. Lack of central pathologic review and independent review of disease progression is also a limitation in a trial setting. Finally, no predictive biomarker that could improve patient selection for nintedanib treatment has been identified in patients with MPM. However, blood samples have been collected in phase II and will be collected during phase III to investigate potential biomarkers.

In conclusion, the addition of nintedanib to standard chemotherapy demonstrated a clinically meaningful benefit in the first-line treatment of patients with MPM. The benefit was evident in patients with epithelioid histology. These findings warrant confirmation and the global, prospectively randomized, phase III trial is recruiting patients with epithelioid MPM to confirm the activity of nintedanib in this patient population.

\section{AUTHORS' DISCLOSURES OF POTENTIAL CONFLICTS} OF INTEREST

Disclosures provided by the authors are available with this article at jco.org.

\section{AUTHOR CONTRIBUTIONS}

Conception and design: Natasha B. Leighl, Arsène Bienvenu Loembé, José Barrueco, Giorgio Scagliotti

Provision of study materials or patients: Federica Grosso, Nicola Steele, Silvia Novello, Anna K. Nowak, Natasha B. Leighl, Martin Reck, Paul Taylor, Jens Benn Sørensen, Mark A. Socinski

Collection and assembly of data: Federica Grosso, Nicola Steele, Anna K. Nowak, Laurent Greillier, Thomas John, Natasha B. Leighl, Martin Reck, Paul Taylor, Jens Benn Sørensen, Mark A. Socinski, Arsène Bienvenu Loembé, Nassim Morsli, Giorgio Scagliotti

Data analysis and interpretation: Nicola Steele, Silvia Novello, Anna K. Nowak, Sanjay Popat, Laurent Greillier, Thomas John, Natasha B. Leighl, Martin Reck, David Planchard, Jens Benn Sørensen, Mark A. Socinski, Ute von Wangenheim, Arsène Bienvenu Loembé, José Barrueco, Nassim Morsli, Giorgio Scagliotti

Manuscript writing: All authors

Final approval of manuscript: All authors

\section{REFERENCES}

1. Taioli $E$, Wolf AS, Camacho-Rivera $M$, et al: Determinants of survival in malignant pleural mesothelioma: A Surveillance, Epidemiology, and End Results (SEER) study of 14,228 patients. PLoS One 10:e0145039, 2015

2. Robinson BM: Malignant pleural mesothelioma: An epidemiological perspective. Ann Cardiothorac Surg 1:491-496, 2012

3. Carbone M, Kanodia S, Chao A, et al: Consensus report of the 2015 Weinman International Conference on mesothelioma. J Thorac Oncol 11: 1246-1262, 2016

4. Røe OD, Stella GM: Malignant pleural mesothelioma: History, controversy and future of a manmade epidemic. Eur Respir Rev 24:115-131, 2015

5. Zalcman G, Mazieres J, Margery J, et al: Bevacizumab for newly diagnosed pleural mesothelioma in the Mesothelioma Avastin Cisplatin Pemetrexed Study (MAPS): A randomised, controlled, open-label, phase 3 trial. Lancet 387:1405-1414, 2016

6. Baas P, Fennell D, Kerr KM, et al: Malignant pleural mesothelioma: ESMO Clinical Practice Guidelines for diagnosis, treatment and follow-up. Ann Oncol 26:v31-v39, 2015 (Suppl 5)

7. Vogelzang NJ, Rusthoven JJ, Symanowski J, et al: Phase III study of pemetrexed in combination with cisplatin versus cisplatin alone in patients with malignant pleural mesothelioma. J Clin Oncol 21: 2636-2644, 2003

8. Garland LL, Chansky K, Wozniak AJ, et al: Phase II study of cediranib in patients with malignant pleural mesothelioma: SWOG S0509. J Thorac Oncol 6:1938-1945, 2011

9. Nowak AK, Millward MJ, Creaney J, et al: A phase II study of intermittent sunitinib malate as second-line therapy in progressive malignant pleural mesothelioma. J Thorac Oncol 7:1449-1456, 2012
10. Dubey $S$, Jänne PA, Krug $L$, et al: A phase ॥ study of sorafenib in malignant mesothelioma: Results of Cancer and Leukemia Group B 30307. J Thorac Oncol 5:1655-1661, 2010

11. Dudek $A Z$, Pang $H$, Kratzke RA, et al: Phase II study of dasatinib in patients with previously treated malignant mesothelioma (Cancer and Leukemia Group B 30601): A brief report. J Thorac Oncol 7: 755-759, 2012

12. Chia PL, Russell PA, Scott $A M$, et al: Targeting the vasculature: Anti-angiogenic agents for malignant mesothelioma. Expert Rev Anticancer Ther 16: 1235-1245, 2016

13. Awasthi N, Schwarz RE: Profile of nintedanib in the treatment of solid tumors: The evidence to date. Onco Targets Ther 8:3691-3701, 2015

14. Hilberg F, Roth GJ, Krssak M, et al: BIBF 1120: Triple angiokinase inhibitor with sustained receptor blockade and good antitumor efficacy. Cancer Res 68:4774-4782, 2008

15. Strizzi L, Catalano A, Vianale G, et al: Vascular endothelial growth factor is an autocrine growth factor in human malignant mesothelioma. J Pathol 193:468-475, 2001

16. Robinson BW, Lake RA: Advances in malignant mesothelioma. N Engl J Med 353:1591-1603, 2005

17. Masood R, Kundra A, Zhu S, et al: Malignant mesothelioma growth inhibition by agents that target the VEGF and VEGF-C autocrine loops. Int J Cancer 104:603-610, 2003

18. Filho $A L$, Baltazar $F$, Bedrossian $C$, et al: Immunohistochemical expression and distribution of VEGFR-3 in malignant mesothelioma. Diagn Cytopathol 35:786-791, 2007

19. Tsao AS, He D, Saigal B, et al: Inhibition of $\mathrm{c}$-Src expression and activation in malignant pleural mesothelioma tissues leads to apoptosis, cell cycle arrest, and decreased migration and invasion. Mol Cancer Ther 6:1962-1972, 2007

20. Khusial PR, Vadla B, Krishnan $H$, et al: Src activates $\mathrm{Abl}$ to augment Robo1 expression in order to promote tumor cell migration. Oncotarget 1 : 198-209, 2010

21. Davidson B, Vintman $L$, Zcharia $E$, et al: Heparanase and basic fibroblast growth factor are coexpressed in malignant mesothelioma. Clin Exp Metastasis 21:469-476, 2004

22. Doebele RC, Conkling $P$, Traynor AM, et al: A phase I, open-label dose-escalation study of continuous treatment with BIBF 1120 in combination with paclitaxel and carboplatin as first-line treatment in patients with advanced non-small-cell lung cancer. Ann Oncol 23:2094-2102, 2012

23. Van Cutsem E, Prenen H, D'Haens G, et al: A phase I/II, open-label, randomised study of nintedanib plus mFOLFOX6 versus bevacizumab plus mFOLFOX6 in first-line metastatic colorectal cancer patients. Ann Oncol 26:2085-2091, 2015

24. Reck M, Kaiser $R$, Mellemgaard $A$, et al: Docetaxel plus nintedanib versus docetaxel plus placebo in patients with previously treated non-smallcell lung cancer (LUME-Lung 1): A phase 3, doubleblind, randomised controlled trial. Lancet Oncol 15: 143-155, 2014

25. Ellis PM, Kaiser R, Zhao Y, et al: Phase I openlabel study of continuous treatment with BIBF 1120, a triple angiokinase inhibitor, and pemetrexed in pretreated non-small cell lung cancer patients. Clin Cancer Res 16:2881-2889, 2010

26. Bousquet G, Alexandre J, Le Tourneau C, et al: Phase I study of BIBF 1120 with docetaxel and prednisone in metastatic chemo-naive hormone-refractory prostate cancer patients. Br J Cancer 105:1640-1645, 2011

27. Byrne MJ, Nowak AK: Modified RECIST criteria for assessment of response in malignant pleural mesothelioma. Ann Oncol 15:257-260, 2004

28. Tsao AS, Harun N, Fujimoto J, et al: Elevated PDGFRB gene copy number gain is prognostic for improved survival outcomes in resected malignant pleural mesothelioma. Ann Diagn Pathol 18:140-145, 2014 
29. Laszlo V, Ozsar J, Klikovits T, et al: Preclinical investigation of the therapeutic potential of nintedanib in malignant pleural mesothelioma. 13th Internationa Conference of the International Mesothelioma Interest Group, Birmingham, United Kingdom, May 1-4, 2016 (abstr)

30. Lakatos D, Hegedus B, Laszlo $V$, et al: Nintedanib-induced motility response in mesothelioma cells. Poster presented at the Semmelweis
Symposium: Molecular Oncology: from bench to bedside. Budapest, Hungary, November 5-6, 2015

31. du Bois A, Kristensen G, Ray-Coquard I, et al: Standard first-line chemotherapy with or without nintedanib for advanced ovarian cancer (AGO-OVAR 12): A randomised, double-blind placebo-controlled phase 3 trial. Lancet Oncol 17:78-89, 2016
32. Lemmens L: Nintedanib in advanced NSCLC Management of adverse events. Lung Cancer Manag 5:29-41, 2015

33. Wang $X$, Wang $X$, Hodgson $L$, et al: Validation of progression-free survival as a surrogate endpoint for overall survival in malignant mesothelioma: Analysis of Cancer and Leukemia Group B and North Central Cancer Treatment Group (Alliance) trials. Oncologist 22:189-198, 2017

\section{Affiliations}

Federica Grosso, Azienda Ospedaliera SS Antonio e Biagio General Hospital, Alessandria; Silvia Novello and Giorgio Scagliotti, L'università di Torino, Azienda Sanitaria Ospedale San Luigi Gonzaga, Turin, Italy; Anna K. Nowak, University of Western Australia, Crawley, and Sir Charles Gairdner Hospital, Nedlands, Western Australia; Thomas John, Olivia Newton-John Cancer Research Institute, Austin Hospital, Heidelberg, Victoria, Australia; Sanjay Popat, The Royal Marsden Hospital National Health Service (NHS) Foundation Trust, London; Nicola Steele, The Beatson West of Scotland Cancer Centre, Glasgow; Paul Taylor, University Hospitals of South Manchester NHS Trust, Wythenshawe, Manchester, United Kingdom; Laurent Greillier, Assitance Publique Hôpitaux de Marseille, Aix Marseille University, Marseille; David Planchard, Institut Gustave Roussy, Villejuif; Nassim Morsli, Boehringer Ingelheim France S.A.S., Paris, France; Natasha B. Leighl, Princess Margaret Cancer Centre, Toronto, Ontario, Canada; Martin Reck, Lung Clinic Grosshansdorf, Airway Research Center North, German Center for Lung Research, Grosshansdorf; Ute von Wangenheim, Boehringer Ingelheim Pharma GmbH \& Co. KG, Biberach, Germany; Jens Benn Sørensen, Rigshospitalet - Finsencentret, Copenhagen, Denmark; Mark A. Socinski, Florida Hospital Cancer Institute, Orlando, FL; Arsène Bienvenu Loembé, Boehringer Ingelheim B.V., Alkmaar, the Netherlands; and José Barrueco, Boehringer Ingelheim Pharmaceuticals Inc., Ridgefield, CT.

Supported by Boehringer Ingelheim.

\section{Support}

\section{Prior Presentation}

Presented at the 17th World Conference on Lung Cancer, December 7, 2016. 


\section{AUTHORS' DISCLOSURES OF POTENTIAL CONFLICTS OF INTEREST}

Nintedanib Plus Pemetrexed/Cisplatin in Patients With Malignant Pleural Mesothelioma: Phase II Results From the Randomized, PlaceboControlled LUME-Meso Trial

The following represents disclosure information provided by authors of this manuscript. All relationships are considered compensated. Relationships are self-held unless noted. I = Immediate Family Member, Inst = My Institution. Relationships may not relate to the subject matter of this manuscript. For more information about ASCO's conflict of interest policy, please refer to www.asco.org/rwc or ascopubs.org/jco/site/ifc.

Federica Grosso

Travel, Accommodations, Expenses: Boehringer Ingelheim

Nicola Steele

Honoraria: Pfizer, Novartis

Consulting or Advisory Role: Merck Sharp \& Dohme, Boehringer Ingelheim, Bristol-Myers Squibb

Research Funding: Merck Serono (Inst), AstraZeneca (Inst), Boehringer Ingelheim (Inst), Bristol-Myers Squibb (Inst), Novartis (Inst), Roche (Inst) Travel, Accommodations, Expenses: Pfizer, MSD Oncology, Boehringer Ingelheim

\section{Silvia Novello}

Speakers' Bureau: AstraZeneca, MSD Oncology, Bristol-Myers Squibb, Roche, Pfizer, Eli Lilly

\section{Anna K. Nowak}

Consulting or Advisory Role: Aduro Biotech, Morphotek, Bayer, AstraZeneca, Sellas Life Sciences, Trizell, Boehringer Ingelheim, Epizyme, Roche

Research Funding: Boehringer Ingelheim (Inst), AstraZeneca (Inst)

Travel, Accommodations, Expenses: Amgen, AstraZeneca, Boehringer Ingelheim

\section{Sanjay Popat}

Honoraria: Pfizer, Boehringer Ingelheim, AstraZeneca, Roche, Eli Lilly, Novartis

Consulting or Advisory Role: Boehringer Ingelheim, Roche, Eli Lilly, Novartis, Pfizer

Research Funding: Boehringer Ingelheim (Inst), Epizyme (Inst), BristolMyers Squibb (Inst), Clovis Oncology (Inst), Roche (Inst), Eli Lilly (Inst)

\section{Laurent Greillier}

Honoraria: Boehringer Ingelheim, Bristol-Myers Squibb, Eli Lilly, Pfizer AstraZeneca, Novartis, Roche

Consulting or Advisory Role: Boehringer Ingelheim, Bristol-Myers Squibb, Roche

Research Funding: Roche (Inst)

Thomas John

Honoraria: Roche, Eli Lilly, Bristol-Myers Squibb, AstraZeneca, Pfizer Consulting or Advisory Role: AstraZeneca, Pfizer, Roche Travel, Accommodations, Expenses: Boehringer Ingelheim, Roche, AstraZeneca

Natasha B. Leighl

Research Funding: Novartis (Inst)

Travel, Accommodations, Expenses: AstraZeneca, Merck Sharp \&

Dohme, Bristol-Myers Squibb, Pfizer

\section{Martin Reck}

Consulting or Advisory Role: Roche, Eli Lilly, MSD Oncology, Merck, Bristol-Myers Squibb, AstraZeneca, Boehringer Ingelheim, Celgene,

Pfizer, Novartis

Honoraria: Roche, Eli Lilly, MSD Oncology, Merck, Bristol-Myers Squibb, AstraZeneca, Boehringer Ingelheim, Celgene, Pfizer, Novartis

Speakers' Bureau: Roche, Eli Lilly, MSD Oncology, Merck, AstraZeneca, Bristol-Myers Squibb, Boehringer Ingelheim, Celgene, Pfizer, Novartis

\section{Paul Taylor}

Travel, Accommodations, Expenses: Pierre Fabre, Bristol-Myers Squibb

\section{David Planchard}

Consulting or Advisory Role: Eli Lilly, Boehringer Ingelheim, BristolMyers Squibb, Pfizer, MSD Oncology, AstraZeneca, Novartis, Roche, Clovis Oncology, Sanofi-Aventis

Research Funding: Novartis (Inst)

Jens Benn Sørensen

Consulting or Advisory Role: Eli Lilly, Boehringer Ingelheim, Merck, Roche

Mark A. Socinski

Honoraria: Genentech

Consulting or Advisory Role: Genentech

Research Funding: Pfizer (Inst)

Ute von Wangenheim

Employment: Boehringer Ingelheim

Arsène Bienvenu Loembé

Employment: Boehringer Ingelheim

José Barrueco

Employment: Boehringer Ingelheim

Nassim Morsli

Employment: Boehringer Ingelheim

Giorgio Scagliotti

Honoraria: Eli Lilly, Pfizer, MSD Oncology, AstraZeneca, Roche

Consulting or Advisory Role: Eli Lilly

Speakers' Bureau: Eli Lilly, MSD Oncology

Travel, Accommodations, Expenses: Bayer 


\section{Acknowledgment}

We thank the patients, their families, and all the investigators who participated in this study, as well as Martha Müller and Derek Velema for their role in the conduct of the study. Medical writing assistance, supported financially by Boehringer Ingelheim, was provided by Suzanne Patel (inVentiv Medical Communications) during the preparation of this manuscript. Boehringer Ingelheim was given the opportunity to review the manuscript for medical and scientific accuracy, as well as for intellectual property considerations.

\section{Appendix}

\section{Phase II inclusion criteria}

- Male or female patients age $\geq 18$ years

- Histologically confirmed malignant pleural mesothelioma (MPM; subtype: epithelioid or biphasic)

- Life expectancy of at least 3 months in the opinion of the investigator

- Eastern Cooperative Oncology Group performance score of 0 or 1

- Measurable disease according to modified RECIST criteria

\section{Key phase II exclusion criteria}

- Previous systemic chemotherapy for MPM

- Prior treatment with nintedanib or any other vascular endothelial growth factor receptor inhibitor

- Patients with sarcomatoid subtype MPM

- Patients with symptomatic neuropathy

- Patients with mild to moderate renal insufficiency (creatinine clearance, 45 to $79 \mathrm{~mL} / \mathrm{min}$ ) taking nonsteroidal antiinflammatory drugs (NSAIDs) with short half-lives unable or unwilling to interrupt NSAIDs for 5 days ( 2 days before, day of, and 2 days after treatment with pemetrexed)

- Patients with mild to moderate renal insufficiency (creatinine clearance, 45 to $79 \mathrm{~mL} / \mathrm{min}$ ) taking NSAIDs with long halflives unable or unwilling to interrupt NSAIDs for 8 days ( 5 days before, day of, and 2 days after treatment with pemetrexed)

- Known hypersensitivity or any contraindications to the trial drugs, including pemetrexed or cisplatin, to their excipients or to contrast media

- Radiotherapy (except extremities) within 3 months before baseline imaging (localized radiotherapy treatment for symptomatic relief is allowed if it occurred at least 2 weeks before random assignment and the measurable disease is outside of the field of radiotherapy)

- In opinion of the investigator, persistence of clinically relevant therapy related toxicity from previous radiotherapy

- Patients who may be eligible for or being considered for radical resection or elective surgery during the course of the study. Note: Prior surgery is allowed if it occurred at least 4 weeks before random assignment, there is complete healing, and there is residual measurable disease

- Radical surgery within 4 weeks before random assignment

- Active brain metastases (eg, stable for $<4$ weeks, no adequate previous treatment with radiotherapy, symptomatic, requiring treatment with anticonvulsants; dexamethasone therapy will be allowed if administered as stable dose for at least 1 month before random assignment)

- Leptomeningeal disease

- Radiographic evidence (computed tomography or magnetic resonance imaging) of cavitary or necrotic tumors or local invasion of major blood vessels by MPM 
Table A1. Locations and Setting of the 18 Sites

\begin{tabular}{|c|c|c|}
\hline Site No. & Site Name and Location & Setting \\
\hline 1 & $\begin{array}{l}\text { Sir Charles Gairdner Hospital, Nedlands, Western Australia, } \\
\text { Australia }\end{array}$ & Hospital \\
\hline 2 & The Prince Charles Hospital, Chermside, Queensland, Australia & Hospital \\
\hline 3 & $\begin{array}{l}\text { Northern Cancer Institute, St Leonards, New South Wales, } \\
\text { Australia }\end{array}$ & $\begin{array}{l}\text { Private institution in partnership with Royal North Shore } \\
\text { Hospital }\end{array}$ \\
\hline 4 & $\begin{array}{l}\text { Austin Health Cancer Clinical Trials Centre, Heidelberg, Victoria, } \\
\text { Australia }\end{array}$ & Major hospital \\
\hline 5 & Princess Margaret Cancer Centre, Toronto, Ontario, Canada & Major teaching hospital \\
\hline 6 & Rigshospitalet, Copenhagen, Denmark & Regional hospital \\
\hline 7 & Institut Gustave Roussy, Villejuif, France & Specialist medical center \\
\hline 8 & Hôpital Nord, Marseille, France & Regional hospital \\
\hline 9 & Hôpital Larrey, Toulouse, France & Regional hospital \\
\hline 10 & $\begin{array}{l}\text { Lung Clinic Grosshansdorf, Airway Research Center North, } \\
\text { German Center for Lung Research, Grosshansdorf, Germany }\end{array}$ & Clinical research unit at community hospital \\
\hline 11 & Azienda Sanitaria Ospedale San Luigi Gonzaga, Turin, Italy & Community hospital \\
\hline 12 & $\begin{array}{l}\text { Humanitas Gavezzeni Unità Funzionale di Oncologia, Bergamo, } \\
\text { Emilia-Romagna, Italy }\end{array}$ & Hospital \\
\hline 13 & $\begin{array}{l}\text { Azienda Ospedaliera SS Antonio e Biagio e Cesare Arrigo, } \\
\text { Alessandria, Italy }\end{array}$ & Hospital \\
\hline 14 & The Royal Marsden Hospital, Sutton, United Kingdom & Hospital \\
\hline 15 & The Royal Marsden Hospital, Fulham, United Kingdom & Hospital \\
\hline 16 & $\begin{array}{l}\text { The Beatson West of Scotland Cancer Centre, Gartnavel } \\
\text { General Hospital, Glasgow, United Kingdom }\end{array}$ & Hospital \\
\hline 17 & Wythenshawe Hospital, Wythenshawe, United Kingdom & Community hospital \\
\hline 18 & University of Pittsburgh Medical Center; Pittsburgh, PA & Hospital \\
\hline
\end{tabular}

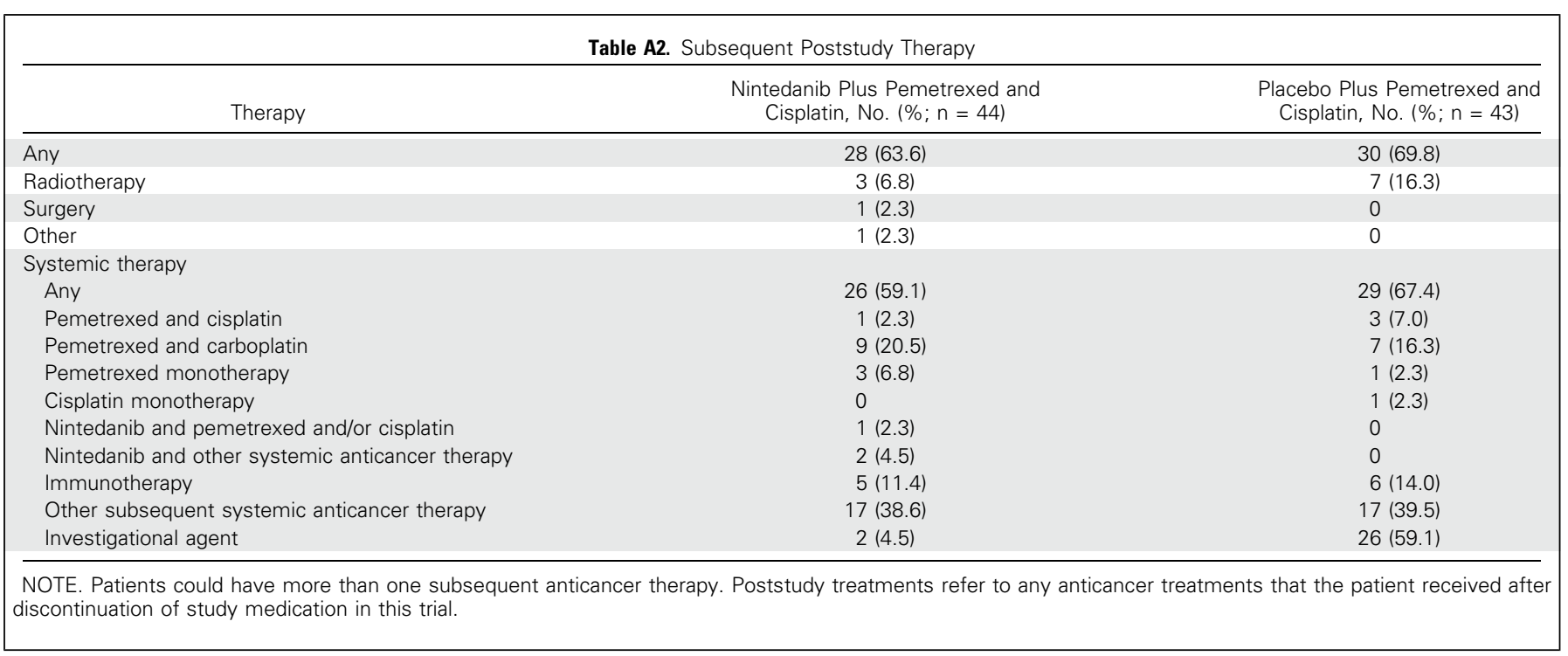

